7 (2016)

D0I: $10.18276 /$ rk.2016.7-06

Agnieszka Smaga

Uniwersytet Kardynała Stefana Wyszyńskiego w Warszawie

\title{
Komparatystyka mediów. Graficzna edycja pisma i obrazu w środowisku cyfrowym - wprowadzenie
}

Przedmiotem badawczym analizy komparatystycznej jest cyfrowa grafika użytkowa i występujące w jej obrębie wzajemne zależności pisma i obrazu. Dwa ostatnie media charakteryzują się z jednej strony określonym stopniem samodzielności i różnymi porządkami wypowiedzi (elementami podstawowymi, sposobami ich wiązania), z drugiej - pozostają w stosunku do siebie w relacji podobieństwa, sporadycznie tożsamości. Pismo i obraz traktowane są zarówno jako formy heterogeniczne, jak i heteronomiczne, ukierunkowane na wzajemne oddziaływania. Dlatego w centrum badawczego zainteresowania postawiono nie "gotowe” media (podobnie jak w matematycznej teorii kategorii ${ }^{1}$ ), ale relacje miedzy nimi, mediacje (Kasperski, 2010: 65-68).

Wskazane zależności cyfrowego słowa i obrazu opisali w sposób dość szczegółowy przede wszystkim Jay David Bolter (2014) oraz Mike Sandbothe (2010). Analizy tychże badaczy stanowią istotny punkt odniesienia lub krytyki dla prezentowanego artykułu. Sandbothe uznał, że oddzielone dotychczas przekaźniki w digitalnym środowisku hipertekstu zmieniają swoje specyficzne cechy i wchodzą w nowe układy - cztery cyfrowe sploty: upiśmiennienie mowy, oralizację pisma, ikonizację pisma i upiśmiennienie obrazu (Sandbothe, 2010: 217-222). Wyszczególnione przekształcenia miałyby akcentować transmedialny charakter stron WWW, gdzie niejednorodne nośniki przekazu tworzyłyby układy zespolenia, integralne całości na poziomie semiotyki i semantyki. Przedmiotem prezentowanej analizy kompara-

\footnotetext{
1 Wnioskowanie w porządku kategorii dystansuje się od teorii mnogości. Zbiór, elementy zbioru przestają być fundamentalnymi pojęciami i schodzą na drugi plan. Najważniejsze okazują się przekształcenia i złożenia interferencji wskazanych mediów.
} 
tystycznej jest pismo i obraz, dlatego zainteresowanie badawcze skierowane zostało na dwa ostatnie transmedialne procesy ${ }^{2}$.

Sandbothe, kierując się badawczą intuicją zasugerował, że istnieje jeden wspólny dla obu mediów (słowa i obrazu) mechanizm, który ujawnia się z poziomu pragmatycznego, czyli funkcjonowania przekazu. Nie analizował tego procesu, podał tylko jego skutki komunikacyjne, mające polegać przede wszystkim na wprowadzeniu słowa i obrazu w ruch oraz związaniu ich z realną rzeczywistością nie tylko na zasadzie symbolicznego do niej odwołania, ale faktycznego, rzeczywistego odniesienia, które dokonuje się w momencie kliknięcia lub dotknięcia cyfrowego znaku (Sandbothe, 2010: 218-219).

Logika wnioskowania „każe” przypuszczać, że wspólny mechanizm funkcjonowania obrazu i słowa w sieci może być osiągnięty tylko przy udziale zbieżnej dla nich techniki generującej, dalej uobecnionej z poziomu prezentacji. Każdy ze wskazanych trzech poziomów cyfrowego przekazu wprowadzony został przez jedno i to samo medium (może w związku z tym należy mówić o transmedium?). Jest nim grafika w odmianie projektowej, użytkowej.

Utożsamienie znaku piśmiennego i ikonicznego, o którym pisał Sandbothe, rzadko pojawia się z poziomu faktycznie prezentacyjnego, ponieważ nie jest ono związane z próbą budowania prostej relacji ich wizualnej identyfikacji. Nie podlega ono w związku z tym procesom znanym z kultury analogowej. Sygnalizowane przez badacza dwie transpozycje - ikonizacja pisma i upiśmiennienie obrazu - nie są więc wynikiem inter-oddziaływań tych dwóch kategorii, a stanowią efekt nadrzędnego w stosunku do nich trans-mechanizmu - kodu graficznego. Należałoby w związku

2 Ikonizacja pisma fonetycznego miała zdaniem Sandbothe’a polegać na traktowaniu tekstu na prawach struktur obrazowych w aspekcie nadania przekazu, tym samym również jego odbioru. Kolejnym przejawem procesu ikonizacji była rehabilitacja pism niefonetycznych (piktogramów, ideogramów). Badacz uznał, że w cyfrowym środowisku ikony funkcjonują na prawach kolejnych elementów „obrazowego pisma”, a ich sekwencje stają się właściwym językiem cyfrowej komunikacji (Zawojski, 1999: 40-41). Następna zdefiniowana przez Sandbothe'a interferencja między mediami polegać miała na upiśmiennieniu cyfrowego obrazu. Autor rozumiał ją jako „oderwanie” obrazu od funkcji naśladowania rzeczywistości. Ikon, podobnie jak pismo, pojawia się w tym przypadku w funkcji autoreferencyjnej, odwołuje się sam do siebie. To znaczy, że „czytamy” go na wzór modelu językowego, czyli od litery do litery, od wyrazu do wyrazu, od zdania do zdania, a nie jako obraz poprzez odniesienie do realnej lub irrealnej rzeczywistości pozaartystycznej. Proces ten realizowany jest w programach graficznych przez operacje „redagowania” obrazu, analogicznie jak pisma, czyli wymiany, przesunięcia. Sandbothe zwracał uwagę, że własności te posiadają cyfrowe obrazy rastrowe już z racji swych uwarunkowań technologicznych. Nie przedstawił jednak analogicznych cech w kontekście grafiki wektorowej, choć ona przede wszystkim podlega owym procedurom zmiany, których jest zresztą zdecydowanie więcej niż dwie wyżej wymienione. 
z tym mówić raczej o grafizacji, która wprowadza właściwe dla siebie procedury obróbki jednego i drugiego medium. To graficzna edycja konstruuje interakcje między cyfrowym pismem i obrazem. Jest ona procesem, w trakcie którego informacjom słownym i obrazowym „nadaje się formę i strukturę, mogącą przekazać w atrakcyjny sposób treść lub nastrój” (Austin, Doust, 2008:9). Wyznaczone przez płaski design cechy stanowią w różnym stopniu o właściwościach komunikatów zarówno analogowych, jak i digitalnych ${ }^{3}$. W przypadku tych drugich konstruują one specyfikę prezentacji i komunikacji w tym środowisku4 ${ }^{4}$. Wprowadzają wielopoziomowe, zmienne interakcje między różnorodnymi semiotycznie kategoriami medialnymi.

Kod graficzny jest odmianą ikonicznego. Dlatego istotny jest dla niego poziom generowania przekazu, czyli fizyczna struktura podłoża, właściwości narzędzi i mechanizmów operacyjno-projektowych, wybranych spośród dużej gamy możliwości. A porządek graficzny w sieci stanowi jeszcze bardziej rozbudowaną i skomplikowaną, kompleksową usługę. Definiuje proces zarówno generowania, jak i prezentacji oraz manipulacji pismem, obrazem, dźwiękiem. Graficzne procedury wynikają bezpośrednio ze specyfiki mechanicznego, cyfrowego zapisu różnogatunkowych danych. Dokonuje się on w postaci zer i jedynek, przechowywanych na twardym dysku komputera w formie bitów. Taka notacja pozwala wielokrotnie powielać informacje bez straty ich jakości oraz dokonywać ich przetwarzania za pomocą matematycznych algorytmów, potem graficznych. Również internetowa transmisja danych, zgodna z protokołem TCP/IP, polega na nieustannym odzyskiwaniu oraz obróbce zakodowanych znaków, na ich odtwarzaniu niezależnie od umiejscowienia w przestrzeni i czasie.

Wskazane mechanizmy - charakterystyczne dla środowiska sieci - kształtują dalej narzędzia, procedury i konwencje cyfrowego projektowania. Graficzne operacje obejmują zarówno pojedyncze znaki, jak i ich grupy, dalej płaszczyznę strony

3 W analizach badawczych drukowanych przekazów (książek, prasy i innych) graficzne medium było jednak najczęściej pomijane, ponieważ go „nie widziano” lub traktowano jako przezroczyste i dlatego mało istotne. Wyjątkiem są prace Philipa Meggsa (1998), Lewisa Blackwella i Davida Carsona (2000).

4 Tryb graficzny rozumiany jest w sieci jako sposób pracy urządzenia zewnętrznego, np. monitora lub drukarki. Poddawane są w nim obróbce poszczególne piksele, czyli pojedyncze elementy, z których tworzony jest obraz na ekranie monitora (również w pamięci komputera). Strategia ta umożliwia przetwarzanie i prezentację map, wykresów, rysunków, fotografii, filmów, animacji itd. Alternatywą dla trybu graficznego jest tekstowy, alfanumeryczny. Definiuje on sposób pracy, w którym są dostępne tylko znaki określonego kodu (np. ASCII). Jest szybki w działaniu, nie umożliwia natomiast działań na pikselach. 
i - wreszcie - przestrzeń sieci WWW. Mają charakter wytwórczy, rękodzielniczy 5 . Dlatego odsyłają w stronę praktyki użytkowania narzędzia. Wybór graficznego instrumentu obróbki przekazu podyktowany jest sposobem użycia go przez odbiorcę-projektanta. Na przykład, edycja w obrębie przyszłego kontentu stron WWW, można dokonać za pomocą takich narzędzi, jak: warstwy lub stosy, selekcje, ścieżki, kształty, kanały, style, kolory, filtry, maski, pędzle, ołówki, rozpylacze, gładziki, gumki, nożyczki, noże, kroplomierze, wiadra z farbą, kaligrafię, cienie, ramki, pipety kolorów, pióra konturów i wiele, wiele innych! Za pomocą wybranych programów edycyjnych (Adobe Photoshop, Adobe Illustrator, CorelDRAW, GIMP i pozostałych) słowa i obrazy mogą być modyfikowane i komponowane na wiele sposobów i w nieskończoność. Poddawane są procesom redakcji (u Sandbotha traktowanej jako jedna z odmian upiśmiennienia obrazu). Odbywa się ona jednak rzadko tylko na prawach pisma (wymiana i przesunięcie, likwidacja znaku w układzie linearnym), częściej na zasadach edycji stricte graficznej: zmniejszenie, powiększenie, duplikowanie, dodawanie, odejmowanie, połączenie, uśrednienie, przekształcenie (obrót, odbicie), skalowanie, blokowanie, grupowanie, ukrywanie i łączenie warstw, wypełnianie, kadrowanie, metamorfozy, zaznaczanie (tutaj cała gama możliwości) itp. Zapis w formie cyfrowej pozwala nie tylko na proste przeprowadzenie wymaganej zmiany, ale również na połączenie w całość różnogatunkowych, oddzielonych od siebie jednostek. Wyświetlane są one jako jedność, ale przechowywane oddzielnie w bazach danych, dlatego każda z nich może być osobno modyfikowana, np. przez funkcje warstwy, kanały, ścieki i inne. Wskazana różnorodność narzędziowa i operacyjna stanowi istotny wyznacznik kodu graficznego.

Cyfrowo i designersko wygenerowane komponenty przekazu ujawniają się odbiorcy przy udziale graficznego interfejsu użytkownika stron WWW i przeglądarki internetowej. GUI definiuje obrazowy sposób przedstawienia informacji (pisma, obrazu i dźwięku) przy udziale komputera oraz interakcji z użytkownikiem, polegającej na „rysowaniu” za pomocą urządzeń wejścia (myszki trackball, touchpad), wejścia-wyjścia (ekran dotykowy) i obsługiwaniu kontrolek, widżetów. Jak można przypuszczać, witryny nie stanowią statycznej formy prezentacyjnej a jej dynamiczną odmianę, tworzoną na bieżąco, poprzez wywołanie oczekiwanej informacji. Faktycznie dopasowują się do interakcji i potrzeb użytkownika. Tym samym designerska obróbka obrazów, dźwięków, tekstów, animacji, które mają stanowić np. kontent internetowych stron, staje się mocno związana z bazami danych - kolejną relacyjną

\footnotetext{
5 „Komputer z urządzenia analitycznego, przeznaczonego do przetwarzania danych stał się krosnem Jacquarda, tworzy media i nimi manipuluje” (Manovich, 2006: 90).
} 
kategorią $-z$ ich indeksowaniem, ekonomią oraz emancypacją użytkownika wobec informacji (Belting, 2007: 49-54). Odchodzi ona od konwencji przedstawienia narzuconej przez kartkę papieru i tworzy mobilne struktury zdolne przede wszystkim do przechowywania i łączenia wielu różnosemiotycznych mediów. Dlatego funkcjonalność cyfrowej grafiki przestaje być zdeterminowana elementem semantycznym, jak w analogowej sztuce projektowania, gdzie słowa traktowane były jako model, opisywały działania lub zdarzenia, które należało przełożyć na graficzny przekaz i dopiero wtedy pełniły one funkcje użytkowe. Tymczasem w środowisku nowych mediów projektowanie staje się

„metaprojektowaniem”. Dziś musimy stworzyć nie tylko tożsamość graficzną, ale także architekturę informacji, system nawigacji i inne struktury, które zostaną wykorzystane przez klienta jako nośniki informacji. W skrócie - projektant grafiki staje się projektantem interfejsu.

(Austin, Doust, 2008: 18)

Zmiana formuły komunikacyjnej, idzie jeszcze dalej.

Użytkownicy interaktywnych mediów sieciowych czasu rzeczywistego mają o wiele większy wpływ na treści, które poznają, niż w przypadku innych mediów. Projektanci, którzy tego nie dostrzegą, skażą swoich odbiorców na błądzenie w poszukiwaniu nowych treści i wskazówek. Podsumowując, projektanci muszą pogłębić swą wiedzę i biegłość w wywoływaniu ludzkich reakcji i zrozumieć, że są uczestnikami, a nie przywódcami.

(Austin, Doust, 2008: 18-19)

To użytkownik staje się współautorem negocjowanego tworzenia, odbierania i przekazywania sensów i dalej znaków, przy niezmienionej jednak rynkowej logice efektywności procesu opracowania przekazu, m.in. graficznego (Nacher: 105-121). $\mathrm{Na}$ proces graficznej edycji obrazu i tekstu mają w związku z tym wpływ, obok cyfrowej struktury zapisu, przede wszystkim uwarunkowania użytkowe.

Grafika zarówno konstruuje, jak i wynika ze specyfiki cyfrowego środowiska. Wprowadza interferencje, sama będąc wynikiem interakcji między opisanymi wyżej właściwościami materiału, technikami a wyborami i praktykami percepcyjnymi oraz użytkowymi w kulturze. Staje się faktycznymi, ciągle trwającymi procesami: z jednej strony intermediacji, z drugiej hipermediacji (Bolter, 2014: 39) - eksponującej właściwości medium i transmediacji - wprowadzającej interakcje między różnosemiotycznymi przekaźnikami. Influencja miedzy poziomem użytkowania i prezentacji daje efekt nałożenia widzialności powierzchni, połączonej z jej destruk- 
cją, na przedmiot estetyczno-stosowany, jakim jest np. strona WWW, wzmacnia ona związek między formą, znaczeniem i funkcją przekazu. W efekcie tworzone jest „opakowanie” (signifiant), które okazuje się jednocześnie „produktem” (signifié) i stanowi rodzaj środka, techniki służącej stymulowaniu oczekiwań użytkowników (Weibel, 2008: 11-28).

W ten sposób rozumiana graficzna edycja „przechodzi” od bycia ikonem na prawach reprezentacji do funkcjonowania przede wszystkim, nawet wyłącznie, jako interfejs ${ }^{6}$. Tak się dzieje często w przypadku mobilnych i responsywnych aplikacji i stron WWW. Tym samym grafika użytkowa i udostępnione przy jej udziale cyfrowe przekazy wymagają specyficznej procedury badawczej - takiej, która rezygnuje z poszukiwania analogowych prototypów obrazu i pisma dla środowiska sieci, czyli z analizy idącej od semiotyki, przez semantykę, do pragmatyki. Nowa metoda poznawcza odwołuje się do zaprezentowanej wyżej specyfiki cyfrowego przekazu, budowanej z poziomu powszechnej komunikacji przy udziale GUI - naukowy namysł „podąża” od oczekiwań i potrzeb użytkownika przekazu, przez jego percepcję, do wygenerowanej semantyki i dalej semiotyki. W punkcie wyjścia badawczego zainteresowania zostaje postawiony realny człowiek, podobnie jak w przypadku projektowania i produkcji GUI stron internetowych ${ }^{7}$. Unikamy w ten sposób rozbieżności, o której mówiła Susan Sontag, między dosłownym znaczeniem przekazu

6 Płaski design zawsze oscylował między tymi dwoma alternatywami, sytuując się bliżej drugiej. Z poziomu prezentacji proponowana przez niego obrazowość, dzięki daleko posuniętej redukcji formy, sprowadzona była do znaku, cechował ją duży stopień uproszczenia, procedura przejścia od różnorodności barwnej, światłocieniowej, formalnej, do graficznej prostoty. Cyfrowa grafika ze względu na jej dużą różnorodność jeszcze lepiej godzi paradoks przejrzystości i nieprzejrzystości typowy dla kultury zachodu. Graficzny interfejs może przybierać obie formy: od pozornej transparentności - np. w grach - do hipermediacji - najlepiej widocznej w interfejsach stron WWW, w szczególności mobilnych i responsywnych (Weibel, 2008: 5-10).

7 Zaproponowana droga poszukiwań badawczych przypomina kolejność wykonywania zadań związanych z tworzeniem witryn internetowych. Pierwszym etapem jest właśnie strategia doświadczenia (analiza poprawności, analiza heurystyczna, testy użyteczności), następnie badanie rynku (określenie odbiorców docelowych, profili użytkownika i interaktywnej mapy handlowej). Witryny WWW, zanim trafią do użytkownika, oceniane są pod kątem ich przyjazności. W tym celu testowane są one na grupach fokusowych, gdzie sprawdzany jest czas wymagany do wykonania konkretnego zadania, analizowane są znaki widziane w pierwszej kolejności i te, które sprawiają największe trudności w realizacji zadań. Okazuje się, że założenia zleceniodawcy i projektanta nie zawsze pokrywają się z oczekiwaniami odbiorców. Grafikowi w trakcie projektowania interfejsów zorientowanych na użytkownika - analogicznie jak naukowcowi - towarzyszy filozoficzny namysł, zgodnie z którym designerskie opracowanie powinno rozszerzać możliwości: percepcyjne, edukacyjne, poznawcze, decyzyjne i praktyczne jednostki i społeczeństwa. Tak rozumiane planowanie oddziałuje na ludzką wiedzę, zachowania i postawy oraz dokonują w ich obrębie zmiany. 
a faktycznymi zachowaniami percepcyjnymi i potrzebami użytkowników. Pytamy w pierwszej kolejności o to, „co robi” kod graficzny, a dopiero później - „co on mówi” (Sontag, 2012: 15). Wtedy cel naukowy analizy komparatystycznej może okazać się zarówno praktyczny, jak i teoretyczny. W pierwszym przypadku przyczyni się on do rozpoznania i usprawnienia działania użytkownika w momencie interakcji; w drugim - związany zostanie z procedurą poznania i nabycia przez niego wiedzy. Dostarczając odbiorcy różnorodnych narzędzi i procedur ich obsługi, wsparty zostaje więc proces konstruowania znaczeń i znaków.

W praktyce użytkownik graficznego interfejsu systemu, aplikacji lub stron WWW oscyluje między trzema alternatywnymi potrzebami i oczekiwaniami. Pojawia się u niego z jednej strony pragnienie obcowania z pozornie rzeczywistym, niezapośredniczonym światem (realistycznym obrazem, fotografią, animacją, filmem). W tym przypadku obserwuje on całą gamę efektów budujących iluzję przejrzystości medium: perspektywę geometryczną, barwną, powietrzną; światłocień, zmienne skale, nasycenia koloru i inne. $\mathrm{Z}$ drugiej strony obecna jest u odbiorcy również fascynacja możliwościami, jakie dają mu same graficzne narzędzia mediacji (personalizacja, wybór, interakcja, linkowanie, zmiana, selekcja, wyróżnienie) ${ }^{8}$. Użytkownik, oglądając nieprzejrzysty, graficzny interfejs systemu, aplikacji (w szczególności na smartfona czy iPada) lub strony WWW odczuwa na początku „przyjemność”. Podziwiając prostotę GUI, połączoną z graficzną atrakcyjnością ikon, rezygnuje z rozumienia ich jako obrazów w funkcji imitacji rzeczywistości. Nie czyta ich również na prawach znaków tekstu: ciągle, linearnie, przyczynowo, skutkowo. Jedynie się nimi zachwyca. Szybko jednak wzrok zaczyna błądzić, poszukując możliwości odkodowania graficznych znaków GUI lub zawartości stron WWW (prowadzających do określonej funkcjonalności lub narzędzia). W tym przypadku pojawiają się praktyczne potrzeby, np. znalezienia informacji, kupna, wypożyczenia, przesłania, udostępnienia, wydrukowania.

Wszystkie trzy warianty odbiorczego kontaktu z przekazem udostępnione są z poziomu graficznego interfejsu. W przypadku interfejsów systemów operacyjnych, aplikacji i mobilnych oraz responsywnych stron WWW coraz rzadziej widoczne jest przechodzenie między dwoma pierwszymi potrzebami odbiorczymi i porządkami przekazu.

Znak pozornie przejrzysty jest raczej eliminowany. Pustą ikonę kontaktów możemy wypełnić zdjęciem, które przywoła realną osobę. Ale czy to robimy? Jeśli

\footnotetext{
8 „Interfejs nie jest przezroczystym oknem, przez które obserwujemy dane komputerowe; wprost przeciwnie - modyfikuje je w sposób zdecydowany” (Manovich, 2006: 142).
} 
tak, to zdjęcie wykonujemy, edytujemy, przycinamy do kształtu kwadratu, koła, prostokąta o określonych rozmiarach i dodajemy własnoręcznie. A w tym przypadku graficzny środek przekazu dokonuje wzmożonej hipermediacji i proponuje całą skalę możliwości modyfikacji: od rozdzielczości, przez balas bieli, kontrasty, dalej kadr, wielkość, kształt i inne bardziej zaawansowane edycje. Interfejs „zapewnia” odbiorcę o swoim doskonałym działaniu, sugerując, że będzie lepszym niż realna fotografia, oferuje bowiem wstęp do pokazywanego świata, przez jego modyfikację.

Z pewnością eksponowane są natomiast znaki nieprzejrzyste, czyli hipermediujące elementy grafiki. W tym przypadku interfejs przyciąga uwagę użytkownika jako czysta, konstelacyjna forma. Pobudza jego zmysł interakcji, kombinatoryki i kreacji. $\mathrm{Na}$ przykład, interfejs systemu operacyjnego Windows na smartfona zbudowany jest z dwuwymiarowych, uproszczonych, jednolicie nasyconych kolorem kafli. Modyfikujemy ustawienia jego ekranu (tła, koloru wiodącego) i ekranu startowego, wprowadzając zdjęcie z aparatu (wykonane własnoręcznie) lub zapisane w bibliotece, dokonując wyboru wzoru i ilości kafli. Regulujemy dalej pozycje poczty, blokady ekranu, udostępniania Internetu, kącika z aplikacjami i wiele innych. Następnie instalujemy kolejne aplikacje i z równie dużą satysfakcją odinstalowujemy je, poszukując możliwości zwiększenia pamięci operacyjnej. Ogromna mnogość narzędzi i przyporządkowanych im funkcji może prowadzić do sytuacji komunikacyjnej, która nie będzie zmierzała w stronę konstruowania przekazu mającego referencje natury obrazowej lub językowej, czyli do rzeczywistości pozainterfejsowej, ale skupi się na samym zmiennym modelowaniu interfejsu. Teoretycznie możemy ulec magii graficznego medium . Ale czy ulegamy?

Dla użytkownika najczęściej nie jest istotna ani cecha transparentności interfejsu (wiązana z jego obliczem obrazowym), ani jego nieprzejrzystości (bliska tekstom pisanym). Tym samym okazuje się mało znaczące, sugerowane na wstępie, rozróżnienie na obraz i pismo. Użytkownikowi zależy najczęściej na szybkim wykonaniu czynności, np. wysłaniu wiadomości, znalezieniu konkretnej informacji, kupnie, sprzedaży, wypożyczeniu, przejrzeniu zdjęć, sprawdzeniu pogody, konta, akcji, poczty itd. Funkcjonalność interfejsu wiąże się w związku z tym z bezpośrednią reakcją ze strony odbiorcy. Owa uczestnicząca aktywność stanowi właściwy proces użytkowej mediacji, dokonywanej przy udziale płaskiego designu.

9 Możliwość manipulacji obrazem na prawach edycji graficznej „odciąga” przedstawienie od funkcji odbicia rzeczywistości. Ikon może sam stawać się alternatywnym, wirtualnym, abstrakcyjnym światem. Taktowany jest wtedy na prawach konstrukcji zarówno w aspekcie technologicznym, jaki i estetycznym, i dalej - użytkowym. 
Graficzna edycja wprowadza operacje zarówno na obrazie, jak i na tekście, dźwięku i ich kombinacjach, ale nie w celu zobrazowania, opisania czy ustrukturyzowania znaczeń, a przede wszystkim - możliwości ich przekazania. W momencie kliknięcia, czyli po zadaniu przez użytkownika (klienta) konkretnego pytania, wskazana różnosemiotyczna zawartość pobierana jest i wyświetlane na ekranie zgodnie z zaprojektowanym wcześniej, obrazowym szablonem. Graficzny interfejs traktuje pismo i obraz z jednej strony jako jednostki heterogeniczne przechowywane w bazach danych w sposób, który umożliwia ich szybkie i łatwe wyszukanie; z drugiej strony - heteronomiczne, czyli wzajemnie na siebie działające w płaszczyźnie prezentacji i manipulacji przekazem. Graficzna edycja umiejętnie łączy oczekiwania odbiorców na dostęp do komunikatu: z jednej strony - precyzyjny (na wzór języka), z drugiej - konstelacyjny (według prototypu ikonicznego) i scala w ten sposób dwie struktury odbioru, uznane w naszej kulturze za odmienne ${ }^{10}$. Pragmatyczna funkcjonalność cyfrowego przekazu rozumiana jest jako mediacja dokładna i syntetyczna (ekonomiczna, redukcyjna), która skutkuje dalej analogicznymi cechami obecnymi na poziomie semiotyki i semantyki, gdzie wyszczególnione trzy płaszczyzny komunikatu cyrkulują w pętli sprzężenia zwrotnego. W środowisku cyfrowym nie mamy do czynienia z „implozją” signifié, a z dominacją i różnorodnością signifiant, ponieważ dopiero forma warunkuje skuteczną, wzajemną komunikację i kreację. Owa eksplozja powierzchni eksponuje kluczowe, pierwszoplanowe cechy pojęć, kosztem ich drugorzędnych jakości. Dla GUI największą wartość ma ten znak, który działa błyskawicznie i celowo, jak strzała wbita w żółte pole na tarczy łuczniczej lub pocisk wcelowany w czarne pole z numerem 10 na tarczy strzeleckiej.

Zintegrowane porządki wypowiedzi stanowiły już o specyfice analogowej grafiki użytkowej. Likwidowały tym samym z poziomu odbiorczego napięcie między rastrem semantycznym, powstałym na prawach pisma, a tym związanym z obrazem. Proces czytania i oglądania trudno było oddzielić od siebie. W odmianie cyfrowej procedury te połączone zostają z praktycznym funkcjonowaniem. Wzajemne zależności w obrębie poziomu funkcjonalnego, semiotycznego i semantycznego będą w środowisku sieci dalej ewoluować, ponieważ odbiorca otrzymał po raz pierwszy tak sprawne narzędzie interakcji, a razem z nim władzę współdziałania, współkreacji, z których z pewnością nie zrezygnuje, zarówno w przypadku poruszania się po stronach WWW, jak i blogach, czatach, wideokonferencjach, grach,

10 Bolter mówi o opozycji tych dwóch poetyk odbiorczych (Bolter, 2014: 85-90, 94-96; Flusser, 2002: 28). 
symulacjach itd. Użytkownik z coraz większą przyjemnością i coraz więcej czasu spędza w świecie cyfrowym, który współtworzy przy użyciu dostępnych narzędzi i procedur graficznych. Użytkowe czytanie/oglądanie skutkuje przemodelowaniem dotychczasowego rozumienia grafiki, a tym samym - wchodzącego w jej skład pisma i obrazu. Proces odbiorczy powoli sam wyznacza rozumienie aktu pisania/ obrazowania i samego pisma/obrazu.

\section{Bibliografia}

Austin, Tricia, Doust, Richard. Projektowanie dla nowych mediów. Przeł. Aleksander Garbiński. Warszawa: Wydawnictwo Naukowe PWN, 2008.

Belting, Hans. Antropologia obrazu. Szkice do nauki o obrazie. Przeł. Mariusz Bryl. Kraków: Universitas, 2007.

Blackwell, Lewis. The Other End of Print: David Carson, Graphic Design, and the Aesthetics of Media. London: Laurence King Publishing, 2000.

Bolter, Jay David. Przestrzeń pisma. Komputery, hipertekst i remediacja druku. Przeł. Aleksandra Małecka, Michał Tabaczyński. Kraków: Korporacja Ha!art, 2014.

Bolz, Norbert. „Estetyka cyfrowa”. Przeł. Jacek Ostaszewski. Pejzaże audiowizualne: telewizja, wideo, komputer. Red. Andrzej Gwóźdź. Kraków: Universitas, 1997.

Bourriaud, Nicolas. Estetyka relacyjna. Przeł. Łukasz Białkowski. Kraków: Muzeum Sztuki Współczesnej MOCAK, 2012.

Bruinsma, Max. Deep Sites, Intelligent Innovation in Contemporary Web Design. London: Thames \& Hudson, 2003.

Chmielecki, Konrad. „Od estetyki intermedialności do estetyki transmedialności. Perspektywy refleksji nad sztuką w kontekście problematyki transgresji mediów i konwergencji kulturowej”. Sztuki w przestrzeni transmedialnej. Red. Tomasz Załuski. Łódź: Oficyna Drukarska Jacek Chmielecki, 2010. http://www.academia. edu/5890983/Sztuki_w_przestrzeni_transmedialnej.

Flusser, Vilém. Writings. Minneapolis: University of Minnesota Press, 2002.

Giaccardi Elisa, Fisher, Gerhard. Meta-Design: A Framework for the Future of End-User Development. http://13d.cs.colorado.edu/_gerhard/papers/EUD-meta-design-online. pdf.

Giaccardi, Elisa. „Metadesign as an Emergent Design Culture”. Leonardo 4 (2005): 342-349.

Górska-Olesińska, Monika. Stowo w sieci. Elektroniczne dyskursy. Opole: Wydawnictwo Uniwersytetu Opolskiego, 2009. 
Hejmej, Andrzej. Komparatystyka. Studia literackie - studia kulturowe. Kraków: Universitas, 2013.

Jenkins, Henry. Kultura konwergencji. Zderzenie starych i nowych mediów. Przeł. Małgorzata Bernatowicz, Mirosław Filiciak. Warszawa: Wydawnictwa Akademickie i Profesjonalne, 2007.

Johnson, Steven. Interface Culture: How New Technology Transforms the Way We Create and Communicate. New York: Basic Books, 1999.

Kasperski, Edward. Kategorie komparatystyki. Warszawa: Wydawnictwo Uniwersytetu Warszawskiego, 2010.

Lenk, Krzysztof. Krótkie teksty o sztuce projektowania. Gdańsk: słowo/obraz terytoria, 2011.

Manovich, Lev. Język nowych mediów. Przeł. Piotr Cypryański. Warszawa: Wydawnictwa Akademickie i Profesjonalne, 2006.

Meggs, Philip B. A History o Graphic Design. New York: Van Nostrand Reinhold, 1998.

Nacher, Anna. „Projektowanie jako negocjacja - między dominacją kodu a ekstazą partycypacji”. Kultura Wspótczesna 3 (2009).

Poulin, Richard. Graphic Design and Architecture, a 20th Century History: A Guide to Type, Image, Symbol, and Visual Storytelling in the Modern World. Beverly, MA: Rockport Publishers, 2012.

Sandbothe, Mike. „Transwersalne światy medialne. Filozoficzne rozważania o Internecie”. Przeł. Krystyna Krzemieniowa. Widzieć, myśleć, być. Technologie mediów. Red. Andrzej Gwóźdź. Kraków: Universitas, 2001.

Sontag Susan. Przeciw interpretacji i inne eseje. Przeł. Małgorzata Pasicka, Anna Skucińska, Dariusz Żukowski. Kraków: Wydawnictwo Karakter, 2012.

Weibel, Peter. „From Data to Images and Back. An Introduction to the Visual Systems of Thorbjørn Lausten”. MAGNET. Thorbjørn Lausten's Visual Systems. Eds. Morten Søndergaard, Peter Weibel. Heidelberg: Kehrer Verlag Heidelberg, 2008. http:// luxpress.dk/wp-content/uploads/2014/12/T.-Lausten-Visual-Systems.pdf.

Widzieć/Wiedzieć. Red. Przemek Dębowski, Jacek Mrowczyk. Kraków: Wydawnictwo Karakter, 2011.

Wiek ekranów. Przestrzenie kultury widzenia. Red. Andrzej Gwoźdź, Piotr Zawojski. Kraków: Rabid, 2002.

Zawojski, Piotr. „Od obrazów pisma do pisma obrazów”. Stowo w kulturze multimediów. Red. Zbigniew Suszczyński, Białystok 1999.

-.--. Interfejs - sztuka interfejsu - „Interface Culture”. http://www.zawojski. com/2014/04/21/interfejs-sztuka-interfejsu-interface-culture-2/\#more-432. 
----. Obrazy elektroniczne - eksplozja produkcji, implozja sensu?, http://www.zawojski. com/2006/04/19/obrazy-elektroniczne-\%E2\%80\%93-eksplozja-produkcji-implozja-sensu/.

----. Sztuka obrazu i obrazowania w epoce nowych mediów. Warszawa: Oficyna Naukowa, 2012.

\title{
Comparative Media Studies. Graphical Edition of Writing and Image in a Digital Environment - Introduction
}

\begin{abstract}
Summary
A digital communique operates with GUI not to depict, describe or structure the meanings but, above all, to transfer them. At the moment of clicking, that is, when a specific question is being asked by the user (customer), specific semiotically varied content is downloaded and displayed on the screen in accordance with the pre-designed, graphic template.

Thus graphical interface treats writing and image on the one hand as heterogeneous units - stored in databases, in a way that makes them quick and easy to find; on the other hand - heteronomous, that is affecting each other at the level of presentation and manipulation of the message. Graphical edition skillfully combines the expectations of recipients concerning the access to the message: on the one hand - precise (along the lines of the language), on the other-economic, reducing (iconic), and it merges in this way two structures of reception, considered in our culture to be different.

Pragmatic functionality of digital message is understood as accurate and synthetic mediation, which results in further analogous features from the level of semiotics and semantics, where the highlighted three planes of the communique circulate in the feedback loop.
\end{abstract}

Keywords: comparative literature, applied graphics, comparative media studies, intermediation, hypermediation, transmediation

Słowa kluczowe: literatura porównawcza, grafika stosowana, komparatystyka mediów, intermediacja, hipermediacja, transmediacja 